\title{
Entre España y América: hacia una clasificación de cuentecillos indianos (con algunos ejemplos)

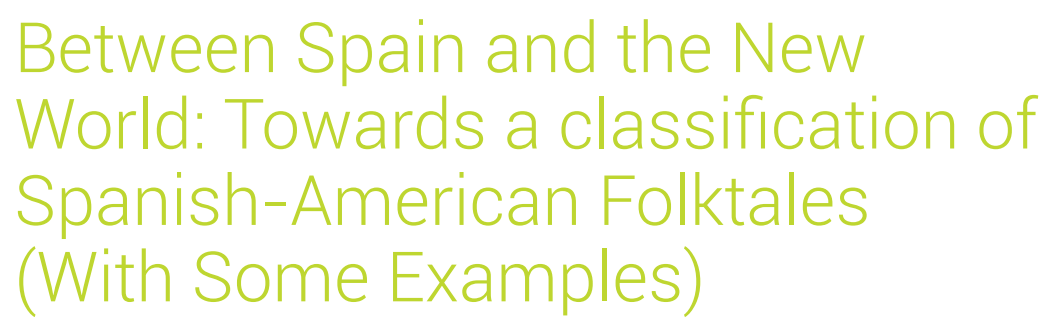

\section{Fernando Rodríguez Mansilla}

Hobart and William Smith Colleges

ESTADOS UNIDOS

Mansilla@hws.edu

[Hipogrifo, (issn: 2328-1308), 7.2, 2019, pp. 269-282]

Recibido: 24-10-2018/ Aceptado: 16-11-2018

DOI: http://dx.doi.org/10.13035/H.2019.07.02.22

Resumen. Este trabajo ofrece un primer esbozo del panorama en torno a los cuentecillos de tema indiano o incluidos en textos que aluden a América, recoge una muestra ilustrativa y presenta las dificultades que entrañan su estudio y su clasificación. Si bien se aboga por recoger todo cuentecillo que se refiera a las Indias, aunque se verifique su origen diverso, se identifica la existencia de un tipo de cuentecillo que parece ser el indiano stricto sensu: el del soldado de la hueste, que se puede mostrar tanto devoto cristiano como tirano cruel.

Palabras clave. Cuentecillos; América; España; soldado; Lancero; ensalmador.

Abstract. This article sketches a first outline on Early Modern folktales about Spanish American colonies or that are included in texts that talk about the New World. Additionally, I present an illustrative anthology of those folktales and discuss the challenges of their study and classification. Although I propose to collect all folktales on the New World, without discrimination, I also identify a type of Early Modern Spanish folktale that is, presumably, the "purest" Spanish-American folktale: folktales about the dual character of the Spanish conqueror, which can be a devoted Christian or a cruel man.

Keywords. Folktales; New World; Spain; Soldier; Lancero; healer. 
Una materia pendiente en los estudios sobre la literatura colonial es la recopilación de cuentecillos tradicionales ambientados en las Indias o cuyo tema es eminentemente indiano. El cuentecillo es «un relato breve, de tono familiar, de intención jocosa, en general de forma dialogada y de aspecto "realista"»". En los cuentecillos indianos que presento, el tono jocoso es variable, aunque siempre se genera, al menos, una sonrisa a causa de la curiosidad o el asombro frente a la anécdota; asimismo, el diálogo se reduce o se deja de lado para desarrollar un tono narrativo noticioso. Con tales advertencias, en este trabajo ofrezco un primer esbozo del panorama en torno a los cuentecillos indianos, recojo un puñado ilustrativo y presento las dificultades que entrañan su estudio y su clasificación. El panorama es complejo, ya que los cuentecillos indianos se pueden encontrar tanto en textos americanos como españoles. Recopilarlos exige cribar la literatura producida en ambas orillas, y asumir un criterio amplio, ya que, según los ejemplos que comentaré, ni todos los cuentecillos aparentemente indianos lo son, ni los que lo son se muestran como indianos a primera vista. Si bien abogo por recoger todo cuentecillo que se refiera a las Indias, aunque se verifique su origen diverso, identifico la existencia de un tipo de cuentecillo que parece ser el indiano stricto sensu: el del soldado de la hueste, que se puede mostrar tanto devoto cristiano como tirano cruel.

\section{CUENTECILLOS INDIANOS DE ORIGEN PENINSULAR}

En primer lugar, no todos los cuentecillos que se encuentren en un texto americano o que aluda a América son estrictamente de origen indiano. Existen cuentecillos españoles transferidos a las Indias, en un mero cambio de ambiente que no impide reconocer su origen medieval europeo. Entre ellos destaca el de «el hombre que volaba». En su Historia general del Pirú, fray Martín de Murúa nos cuenta el caso ocurrido en Carabaya, famoso centro minero, donde se vio

ir volando un hombre, el cual al parecer venía de hacia levante. Traía tendidos los brazos, como quien se echa a andar. Era barbicano, vestido de negro y calzadas unas botas de camino, con una gorra de las que se usan en la corte. [...] Llegó la fama, como quien poco se descuida, a oídos del comisario, el cual envió luego a llamar y debajo de juramento le contó [el testigo] la verdad del caso².

La popularidad del cuentecillo en España se verifica en las cuatro versiones que recoge Maxime Chevalier bajo el título «Solo le falta la cola»3${ }^{3}$. En estas versiones, los voladores apenas planean con sus alas artificiales, se estrellan bien pronto y se cuenta lo golpeados que acaban. Su caída da paso a una explicación del volador a su fracaso que genera la comicidad del cuentecillo: se cayó porque le faltaba la cola propia de las aves, detalle que él olvidó antes de echarse a volar. Incluyo aquí la versión de la Miscelánea de dichos para evidenciar el contraste con el que recoge Murúa en el Perú:

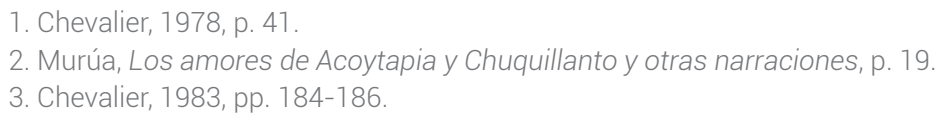


Un monje hubo en Alemania llamado Mero, el cual, en su juventud, antes que en letras estuviese maduro, determinó de ponerse plumas en las manos y en los pies para volar, como la fábula de Dédalo cuenta, creyendo ser verdadera, y tomando aire de encima de una torre voló por espacio de más de un estadio. Mas con la violencia del viento y torbellino y con el temor que su temerario hecho le ponía, hubo de caer en tierra y quebrándose las piernas quedó toda la vida debilitado. Después decía la causa de su caída haber sido por no haberse acordado de poner cola 4 .

La diferencia de la versión indiana es que, asumiendo el conocimiento del cuentecillo en la península, relata el vuelo exitoso, transmitiendo asombro. Además, intuye la incredulidad del lector cuando se refiere que el testigo, Pedro de Bolumbiscar, era «hombre de muy gran crédito» ${ }^{5}$ y se añade que el comisario del lugar buscó que jurase la veracidad de lo dicho. Así, lo que en España se cuenta como anécdota risible, en América es noticia asombrosa, con detalles realistas destacados (como la ropa del volador, datos del lugar y testigos) y, de acuerdo con su inclusión en una crónica histórica, su tratamiento pretende ser serio y veraz. Sin embargo, el origen del cuentecillo indiano está en España, de allí su discrepancia en la perspectiva narrativa. Fradejas Lebrero, quien recoge también varias versiones españolas del cuentecillo, refiere las dos versiones más antiguas, localizadas en Irán y en Inglaterra6.

El cuentecillo del hombre que vuela en América, entonces, trueca el chiste del inventor que justifica su fracaso por el del asombro frente a lo que puede pasar en un espacio propio de la maravilla como el Nuevo Mundo. Quien leyera el cuentecillo según lo cuenta Murúa recordaría las versiones españolas y se sonreiría pensando en la posibilidad de que eso pueda ocurrir en tierras tan lejanas y extrañas. El cuentecillo se naturaliza como indiano y gana en admiración, en desmedro del humor frente al fracaso del inventor loco, según se narraba en el Viejo Mundo.

Un caso de cuentecillo ambientado en Indias que es igualmente de origen peninsular, pero resulta engañoso en primera instancia, es el que puede denominarse «el brindis de los curacas», el cual se encuentra en el capítulo XVIII del libro III de los Comentarios reales del Inca Garcilaso de la Vega: dos curacas o caciques locales están enemistados, uno de ellos intenta matar al otro ofreciéndole brindar con una copa envenenada en medio de una celebración y la víctima inteligentemente obliga al traidor a beber del vaso que le acaba de tender. Lleno de ira, el victimario, presionado por encontrarse en público, debe tomar el veneno y morir con el mismo instrumento con el que pretendía matar a su rival.

El cuentecillo ha gozado de fortuna en la literatura peruana, pues se transformó en una tradición de Ricardo Palma, en el siglo XIX, y luego en un extenso relato de los Nuevos cuentos andinos (1938) del indigenista Enrique López Albújar. Al provenir del Inca Garcilaso, los críticos peruanistas lo filiaron de inmediato como autóctono, pero se trata de una adaptación de un pasaje de la historia medieval española que

4. Fradejas Lebrero, 2008, p. 217.

5. Murúa, Los amores de Acoytapia y Chuquillanto y otras narraciones, p. 19.

6. Fradejas Lebrero, 2008, pp. 43-46. 
hasta generó el romance «La condesa de Castilla traidora», pues su protagonista original era una mujer envenenadora. La anécdota aparecía en la Crónica general de Alfonso X que refundió Florián de Ocampo en el siglo XVI y a la que pudo acceder el Inca Garcilaso fácilmente?

\section{UN CUENTECILLO INDIANO DILUIDO}

Hemos comentado dos cuentecillos recogidos en textos americanos que, no obstante, tienen claro origen peninsular cuando se profundiza en sus fuentes. Un caso especial, en el que el cuentecillo indiano se ha infiltrado en la lengua peninsular hasta haber perdido la referencia americana, es el que puede llamarse «Jugar el sol antes que nazca». La frase se encuentra explicada en el Vocabulario de refranes de Gonzalo Correas: «Juega el sol antes que nazca; jugará el sol antes de nacer. Dícese del muy tahúr»8. Tal vez Correas se apoya en el Tesoro de Covarrubias, ya que en la entrada «juego» el lexicógrafo anota su significado para referirse al jugador empecinado: «Jugar el sol antes que salga, vale el jornal del día siguiente»9. Sin mayor contexto, Covarrubias logra explicarlo sin recurrir a su origen indiano, pues asume «el sol» como el jornal o paga diaria que el tahúr apuesta antes siquiera de cobrar. La frase aparece en La pícara Justina para caracterizar ingeniosamente al marido jugador: «Jugaba el sol antes que naciese, y no digo yo el sol, que con quedarme a buenas noches se acabara, pero jugaba toda la noche» ${ }^{10}$. Tan trillada era la frase a inicios del siglo XVII que Quevedo la incluye en su lista de bordoncillos enfadosos de la «Pregmática que este año 1600 se ordenó»: «Juega el sol antes que sale» »1.

Ahora bien, en el cap. XII de la Historia moral, Josef de Acosta refiere una explicación ingeniosa para el origen específicamente indiano del refrán, conectándolo con la descripción del templo del Sol en el Cuzco, también conocido como Coricancha:

En esta misma casa [el templo dedicado al sol] estaba el Punchao, que era un ídolo del sol de oro finísimo con gran riqueza de pedrería [...] En los despojos deste templo riquísimo dicen que un soldado hubo aquella hermosísima plancha de oro del sol y, como andaba largo el juego, la perdió una noche jugando; de donde toma origen el refrán, que en el Pirú anda de grandes tahúres, diciendo «Juega el sol antes que nazca» ${ }^{12}$.

Acosta recupera todo el ingenio de la frase, basado en una dilogía, con el relato de la larga noche de juego. El tahúr apostó «el sol» (la plancha de oro) antes de que el astro ciertamente apareciera. El Inca Garcilaso de la Vega reconoce tomar parte de la información de Acosta y le suma su propio conocimiento personal para este

7. Remito a Rodríguez Mansilla, 2014, en torno al origen, la trasmisión y adaptación del cuentecillo en la literatura peruana.

8. Correas, Vocabulario de refranes, p. 274

9. Cov., p. 1144.

10. López de Úbeda, La pícara Justina, p. 849.

11. Quevedo, Prosa festiva completa, p. 153.

12. Acosta, Historia natural y moral de las Indias, p. 168 
pasaje de los Comentarios reales (libro III, cap. XX), que confirma el origen totalmente indiano del refrán:

Esta figura del Sol cupo en suerte, cuando los españoles entraron en aquella ciudad [Cuzco], a un hombre noble, conquistador de los primeros, llamado Mancio Serra de Leguizamo, que yo conoscí y dejé vivo cuando me vine a España, gran jugador de todos los juegos, que, con ser tan grande la imagen, la jugó y perdió en una noche. De donde podremos decir, siguiendo al Padre Maestro Acosta, que nació el refrán que dice: «Juega el Sol antes que amanezca» ${ }^{13}$.

El cuentecillo «Juega el sol antes que nazca», que gozó de gran popularidad, no llamaba la atención, en primera instancia, como indiano, aunque en Acosta y Garcilaso se reivindica su origen. Se trata, como señalamos, de un cuento indiano que se diluye sin dificultad dentro de las frases hechas del lenguaje del siglo XVII, sin reclamar su vínculo con la conquista del Perú. Por último, puede especularse que la expresión, de raíz indiana, tiene su origen en una algo anterior de origen peninsular y significado semejante (señalar al vicioso jugador), «Jugar el sol en la pared», la cual aparece en La Lozana andaluza (1528) y cuyo origen no alcanzo: «Mi padre nos dejó una casa en pleito por ser él muy putañero y jugador, que jugara el sol en la pared» ${ }^{14}$. De hecho, los editores de este pasaje de La Lozana suelen aludir al ejemplo ya apuntado de La pícara Justina o a la breve glosa de Correas para ilustrar su significado, que consideran una variante de la frase que genera el cuentecillo indiano. Sin embargo, la transición de «sol en la pared» a «el sol antes que nazca» provendría de una anécdota asociada con un botín riquísimo desperdiciado por el vicio del juego en una aventura de ultramar. "Juega el sol antes que nazca», con la dilogía de sol como 'astro' y 'plancha de oro', evoca así un pasaje de la historia americana que se perdió pronto al volverse frase hecha.

\section{CUENTECILLOS INDIANOS PROPIAMENTE DICHOS}

Un caso bien diferente, en el que el cuentecillo se refiere como indiano en ambas orillas del Atlántico, es el que denomino «el salmo de Lancero». Este cuentecillo sería definitivamente indiano según todas las fuentes que he podido consultar. Además, sus detalles exigen un contacto con la realidad americana para que la anécdota funcione. La glosa de Correas dice así:

El salmo de Lancero. Díjose en las Indias por un soldado así llamado, de los primeros que allá pasaron, que con unas palabras buenas que decía, haciendo la señal de la cruz sobre las heridas, sanaban luego; atribúyese a la voluntad de Dios para fundar allá la fe en los indios, más que a ensalmos inciertos. Aplícase a cosas útiles que parece se obran u obraron por milagro ${ }^{15}$. 
En el capítulo XXVII de la Historia moral la anécdota se narra casi idénticamente:

Lancero fue en el Pirú un soldado, que no se saben dél más méritos que ser soldado. Decía sobre las heridas ciertas palabras buenas haciendo la señal de la cruz, y sanaban luego: de donde vino a decirse, como por refrán, «el salmo de Lancero». Y examinado por los que tienen en la iglesia autoridad, fue aprobado su hecho y oficio ${ }^{16}$.

Dos rasgos de Lancero destacan cuando se confronta la versión de Correas con la de Acosta. Primero, para Correas, el soldado es «de los primeros que allá pasaron», por lo que su existencia se remontaría a inicios del XVl; mientras que Acosta lo sitúa en la conquista del Perú, es decir al menos en la década de 1530. Además, se observa la imprecisión del jesuita cuando señala que «no se saben dél más méritos que ser soldado», con lo que su identidad queda en la bruma casi legendaria, como se confirmará con los otros testimonios sobre el misterioso personaje. El elemento común entre Correas y Acosta es el carácter evangelizador del soldado, ya que el paremiólogo resalta que las sanaciones serían «voluntad de Dios para fundar allá la fe en los indios», mientras que el jesuita incorpora la anécdota de Lancero en un capítulo de su crónica titulado «De algunos milagros que en las Indias ha obrado Dios en favor de la fe, sin méritos de los que los obraron». El pasaje sobre Lancero sigue al de las acciones, también calificadas como evangelizadoras, que llevaron a cabo Álvar Núñez Cabeza de Vaca y sus compañeros en la Florida. Esta proximidad entre los personajes (Lancero y los cautivos floridianos) también se observa en otros testimonios, donde llegan a confundirse hasta volverse uno solo.

Más interesante para el conocimiento del enigmático Lancero se muestra el capítulo CXXIX de la Historia verdadera de la conquista de la Nueva España. Para Bernal Díaz, hay un soldado, Lencero (nótese la variante en la primera vocal), al que se atribuye otra anécdota, «el socorro de Lencero». Dicha anécdota provee un mensaje más bien burlesco, ya que este Lencero capitanea un grupo de soldados enfermos que no van a ser de gran ayuda en la batalla:

Venía por capitán dellos un soldado que se decía Lencero, cúya fue la venta que agora se dice de Lencero. Y cuando llegaron a Tascala, como venían dolientes y flacos, muchas veces por nuestro pasatiempo y burlar dellos decíamos: «El socorro de Lencero», que venían siete soldados y los cinco hipates e llenos de bubas, y los dos hinchados con grandes barrigas. Dejemos de burlas y digamos lo que allí en Tascala nos aconteció... 17

Tras el encuentro con los soldados bubosos o indispuestos, «el socorro de Lencero» se vuelve frase proverbial entre la hueste para ridiculizar refuerzos inútiles ${ }^{18}$.

16. Acosta, Historia natural y moral de las Indias, p. 269.

17. Díaz del Castillo, Historia verdadera, p. 495.

18. Por cierto, la construcción de la frase parece evocar una ambientada en la península y un tanto diferente en su significado: el «Socorro de Escalona», que se refiere a la ayuda que llega tarde. Así se ejemplifica en La Lozana andaluza, p. 184 y lo glosa Covarrubias: «El socorro de Escalona, cuando le llega el agua es quemada la villa toda» (p. 805). 
Curiosamente, Bernal, en el capítulo CLI de su libro, atribuye el poder de curar con las manos y un rezo que otros textos atribuyen a Lancero a un tal Juan Catalán:

Cuando en la noche nos despartía curábamos nuestras heridas con quemárnoslas con aceite, e un soldado que se decía Juan Catalán, que nos las santiguaba y ensalmaba, y verdaderamente digo que hallábamos que Nuestro Señor Jesucristo era servido darnos esfuerzo, demás de las muchas mercedes que cada día nos hacía, y de presto sonaban ['sanaban']. Y heridos y entrapajados habíamos de pelear desde la mañana hasta la noche ${ }^{19}$.

No cuesta imaginar que, de boca en boca, se confundiera a este Juan Catalán con el memorable Lencero, el del «socorro», quien sería muy conocido en México, por tener una venta famosa, según indica el mismo Bernal Díaz al mencionarlo en la extensa nómina de los soldados que pasaron de Cuba a México con Hernán Cortés: «E pasó también otro soldado que se decía por sobrenombre Lencero, cuya fue la venta que agora se dice "de Lencero", que está entre la Veracruz e la Puebla; fue buen soldado, e murió de su muerte [es decir, de causas naturales]» ${ }^{20}$.

Añade Bernal que «Lencero» era sobrenombre, por lo que no contamos con el nombre real del soldado, cuya figura se vuelve, de nuevo, evanescente, a causa de la confusión con un tal Juan Catalán. Recordemos que Acosta ubica a Lancero en Perú y admite que «no se saben dél más méritos que ser soldado», dentro de un capítulo en el que refiere la historia de Cabeza de Vaca, ampliamente conocida, junto a las apariciones, más famosas y avaladas por otros textos de la época, de la Virgen María y el Apóstol Santiago durante el cerco del Cuzco.

Salvando la confusión de Bernal, si se considera «Lencero» una variante de «Lancero», resulta atractivo considerar que se trata de un nombre genérico, que es operativo tanto en México como en Perú, en cualquier territorio americano en el que se produce un episodio de conquista: el que porta la lanza. Lancero sería, entonces, un arquetipo y no una persona concreta, en este caso un soldado caritativo que sana a sus compañeros y pelea, por la difusión de la fe católica, en las empresas militares americanas. Lancero o Lencero es nadie, pero a la vez puede referirse a cualquiera de la hueste. Recojo aquí el sentido de «arquetipo» como modelo o figura mítica, en términos de Mircea Eliade: la memoria colectiva es ahistórica y suele transmitir la repetición, como en estos cuentecillos, de un comportamiento que se considerase ejemplar y descartar actos individuales ${ }^{21}$.

La figura del soldado devoto al que se asocia con la lanza recuerda a Longinos, santo legendario. En textos del Siglo de Oro se le identifica como noble, llamándolo "caballero Longinos», como en la primera parte de El caballero puntual22, o también «San Longinos». En otros textos auriseculares se dice que Longinos murió sirvien-

19. Díaz del Castillo, Historia verdadera, p. 621. En nota a este pasaje, el editor Guillermo Serés menciona testimonios paralelos de Francisco Cervantes de Salazar y Antonio de Herrera que atribuyen este don de ensalmar a una mujer, Isabel Rodríguez.

20. Díaz del Castillo, Historia verdadera, cap. CCV, p. 1028.

21. Eliade, 1971, p. 44.

22. Salas Barbadillo, El caballero puntual, p. 19. 
do en un hospital de Mantua, asociándolo con la orden de la Sangre de Cristo, o bien entregando su vida como mártir en Capadocia; aunque esta faceta seria coexiste con la satírica, en la que se le identifica como judío ${ }^{23}$. Restringiéndonos a su tratamiento serio, el único pertinente aquí, Lancero se asemeja a Longinos en su cristianismo que se plasma en la atención a sus compañeros enfermos.

«El salmo de Lancero» es, quizás, el cuentecillo de Indias más popular, de seguro porque sintetizaba el carácter providencial de la conquista y por su rápida transmisión oral en España. En el manuscrito Liber facetiarum de Luis de Pinedo, datado hacia 1555, se habla, en el cuentecillo núm. 75, de un tal Rojas, capitán de artillería retirado, actualmente vecino de Peñafiel. Este soldado veterano «había estado en Indias muchos años, perdido, según él decía, porque perecieron sus compañeros todos» (como Cabeza de Vaca) y «contando cosas de gran admiración, entre otras dijo tres o cuatro maravillosas» sobre América. Una de ellas es «que le adoraban los indios por hijo del Sol y que había hecho muchos milagros sanando enfermos de repente» ${ }^{24}$. Aquí se mezcla la imagen del conquistador como figura semidivina, o sea como «teule» en México y como «viracocha» en Perú, con lo que se refuerza la idea del soldado como difusor de la religión católica en las Indias, de la mano del convencimiento de los nativos en torno a la superioridad del conquistador, al que se le facilitó así la empresa.

Lo curioso es que la primera edición de los Naufragios que conocemos es la de Zamora en 1542 y, alrededor de una década después, el Liber Facetiarum nos habla de un veterano (su nombre es lo de menos) que sanaba y era considerado una divinidad entre los indígenas; ello permite pensar que el testimonio de Cabeza de Vaca caló pronto entre su audiencia. El conquistador destinaba los capítulos XX-XII de los Naufragios a relatar las actividades por las que ganó muchas atenciones de los nativos, santiguando a los enfermos. Como estos mejoraban, «en todo este tiempo [cerca de ocho meses] nos venían de muchas partes a buscar, y decían que verdaderamente nosotros éramos hijos del Sol» ${ }^{25}$. Cabeza de Vaca es cauto cuando narra sus aventuras en primera persona, por ello nunca habla de «milagros», como sí se dice, con ligereza, en el Liber Facetiarum. El protagonista de los Naufragios habla de «maravillas»:

Ya ellos [los indios] tenían noticia de nosotros y cómo curábamos, y de las maravillas que nuestro Señor con nosotros obraba, que, aunque no hubiera otras, harto grandes era abrirnos caminos por tierra tan despoblada [...] y poner aquellas gentes en corazón que nos tratasen bien ${ }^{26}$.

23. Recojo estos datos sobre Longinos en el Siglo de Oro de las notas complementarias de E. López Martínez a su edición de un texto de Salas Barbadillo (El caballero puntual, pp. 267-268). Por otro lado, hay menciones de Longinos en textos españoles medievales como el Poema de mio Cid (vv. 352-357) y el célebre milagro de Teófilo incluido en los Milagros de Nuestra Señora (XXV, 827) de Berceo. Estas referencias avalarían su popularidad en la tradición literaria de la época.

24. Fradejas Lebrero, 2008, p. 240.

25. Núñez Cabeza de Vaca, Naufragios, p. 158.

26. Núñez Cabeza de Vaca, Naufragios, p. 152. 
Estas «maravillas» que cuenta Cabeza de Vaca, como parte de su peregrinación por tierras americanas ignotas, en la cual contó con la ayuda de Dios, según relata, para sobrevivir, se propagaron rápidamente y empezaron a ser llamadas «milagros». Esto lo muestra desde temprano un texto como el de Pinedo, pero también La Florida del Inca (1605), casi medio siglo después de los Naufragios. En el capítulo III del libro I, el Inca Garcilaso se refiere, en un contexto crítico, a Cabeza de Vaca y sus compañeros así: «Llegaron a hacer milagros en su nombre [en el nombre de Dios], con los que cuales habían cobrado tanta reputación y crédito con los indios, que les adoraban por dioses» ${ }^{27}$. Sin embargo, más adelante en su texto, Garcilaso matiza lo de «hacer milagros», cuando habla de cómo los indígenas adoptaron la cruz puesto que «tuvieron noticia de los beneficios y maravillas que Alvar Núñez Cabeza de Vaca y Andrés Dorantes y sus compañeros, en virtud de Jesu Cristo Nuestro Señor, habían hecho por las provincias que anduvieron de la Florida» 28

Poniéndolo en contacto con Cabeza de Vaca y el inédito Rojas, que bien podría ser considerado un mero reflejo del primero, el misterioso Lancero se distingue por no caer en el efectismo de haber sido considerado «hijo del Sol». De hecho, Rojas cae en el tópico del miles gloriosus, aquel soldado que cuenta sus presuntas hazañas ocurridas en un lugar muy lejano hace tanto tiempo que nadie más puede verificarlas: entre tantas cosas, es posible que esté atribuyéndose hechos que no llevó a cabo, en la senda de los «cuentos de mentira», aquellos que adopta un narrador en primera persona, recurso típico del Siglo de Oro ${ }^{29}$. De esa forma, ni Cabeza de Vaca ni Rojas admiten parangón estricto con Lancero, dado que ambos cuentan su historia en primera persona y no dejan de incurrir en un exhibicionismo propio de la autobiografía.

A diferencia de ellos, de Lancero recibimos testimonios breves que enfatizan su carácter de arquetipo y no de persona real, mucho más al resaltar que se le conoce tan solo por aquel sobrenombre. Es presumible que la figura, de dimensiones míticas, de Lancero, tenga su origen en la experiencia de Cabeza de Vaca, personaje real (de hecho, el primero) que se atribuyó el don de ensalmar en las Indias. A partir de este sujeto histórico se habría desatado una serie de cuentecillos que acabaron por delinear a Lancero. El desconocido Rojas del Liber facetiarum sería, en esa trayectoria, un paso más, o incluso un desvío, en el camino de la consolidación de Lancero.

Una posible interpretación de Lancero, entendido como encarnación del soldado modelo (por su caridad y devoción) en Indias, sería la de constituir una recreación positiva del fanfarrón del Renacimiento, el que al pasar a tierras americanas vive una nueva aventura y vuelve a la patria con el botín de su experiencia. Como lo estudió Lida de Malkiel, el fanfarrón del teatro del XVI se alimenta del personaje

27. Garcilaso de la Vega, La Florida del Inca, pp. 16-17. En ese pasaje, el cuzqueño cuestiona, en las líneas siguientes, el pronto regreso a España de Cabeza de Vaca y los otros sobrevivientes para «pretender nuevas gobernaciones» de la Corona, en merced de su aventura. Dados los beneficios divinos que se mostraban en su peregrinación, sostiene el cuzqueño, los hombres debieron quedarse un tiempo más para ayudar a propagar la fe.

28. Garcilaso de la Vega, La Florida del Inca, libro V, parte I, cap. II, p. 336.

29. Bataillon, 1968, p. 49. 
de Centurio de La Celestina y en Italia se le deformó hasta convertirlo en el soldado o capitán español valentón ${ }^{30}$. Más recientemente, Sánchez Jiménez ha analizado cómo los rasgos ridículos (arrogante, fanfarrón, violento, galante, etc.) de este personaje de la comedia italiana, conocido como «il capitano Spavento», se incorporaron a comedias de Lope de Vega y, al parecer, el público los admitía con naturalidad, aceptando prejuicios extranjeros sobre los españoles, aunque resignificándolos, como parte de la identidad nacional ${ }^{37}$. Por otra parte, Miguel Martínez ha explorado cómo el espacio público del mentidero a inicios del siglo XVII es aquel en que el soldado veterano, fanfarrón, empobrecido y pretendiente eterno, se mezcla con el mundo marginal ${ }^{32}$. Lancero sería, dado ese contexto cultural de imágenes soldadescas negativas, una versión dulcificada del fanfarrón que, en las tablas o en los bajos fondos, era protagonista cómico y degradado de las virtudes militares españolas.

No es de extrañar, por ello, que ya en pleno siglo XVII las representaciones del soldado en la literatura cómica incluyan una referencia a una falsa santidad asociada con el don de curar. En El sagaz Estacio de Alonso J. de Salas Barbadillo, se presenta como aspirante a maridillo a un soldado de Flandes que «cura por ensalmo y hace parches para las que tienen mal de madre», ante lo cual la dama comenta: «Lo de curar por ensalmo tiene algunas veces su parte de embuste, y más cuando cae en hombres de mala vida [como lo sería el soldado] que quieren hacerse autores de milagros al mismo tiempo que se ejercitan en torpes vicios» ${ }^{33}$. De manera similar, en el entremés «El convidado», de Pedro Calderón de la Barca, un soldado exclama, para zafarse de una burla, que acaba de curarse de repente apelando a la misma gracia: «Ninguno su lugar deje, / porque esto es cosa que pasa / mil veces por mí, que tengo / cierta gracia, gratis data / de milagros.... ${ }^{34}$. De inmediato todos en el escenario afirman que se trata de un santo, a lo que el soldado replica: «Yo no digo nada, pero / algo hay de eso. Comamos / que después oirán bien raras / cosas de mis devociones» ${ }^{35}$. Es evidente que nos hallamos en estos ejemplos ante la degradación, en clave satírica, del arquetipo del devoto soldado ensalmador cuya historia empezó a transmitirse en crónicas americanas y ahora se ha mezclado con la figura del pendenciero e hipócrita veterano que ronda las calles madrileñas.

Con todo, como en la cultura popular se manejan oposiciones binarias, junto al arquetipo de Lancero, soldado devoto, encontramos a su opuesto: el soldado cruel, que se identifica con el rebelde o el tirano. Es el caso de Francisco de Carvajal, rebelde lugarteniente de Gonzalo Pizarro, a quien se le atribuyen cuentecillos que configuran un pequeño ciclo. Recopilados tanto por Francisco López de Gómara como por Diego Fernández, el Inca Garcilaso de la Vega ofrece su propia selección compuesta de trece cuentecillos, que se ha vuelto canónica, en dos capítulos del

30. Lida de Malkiel, 1966

31. Sánchez Jiménez, 2016, pp. 178-203.

32. Martínez, 2016, pp. 184-186.

33. Salas Barbadillo, El sagaz Estacio, p. 102.

34. Calderón de la Barca, «El convidado», Entremeses, jácaras y mojigangas, vv. 261-264.

35. Calderón de la Barca, «El convidado», Entremeses, jácaras y mojigangas, vv. 266-269. 
libro V de la Historia general del Perú: el capítulo XLI, «El vestido que Francisco de Carvajal traía y algunos de sus cuentos y dichos graciosos» (seis cuentecillos), y el XLII, «Otros cuentos semejantes, y el último trata de lo que le pasó a un muchacho con un cuarto de los de Francisco de Carvajal» (siete cuentecillos). Al historiador cuzqueño le debemos un diseño original de Carvajal como un Sileno, un anciano que conjuga sabiduría y humor, vestido de verde (color de los bufones) y montado en mula (montura plebeya). Con ese perfil tan nítido y singular en las crónicas de Indias, Carvajal se erige como un personaje festivo tan memorable como el doctor Villalobos o el gracioso Velazquillo en recopilaciones peninsulares ${ }^{36}$. Entre sus cuentecillos, quisiera comentar el que se puede denominar «la prueba del fraile»:

Andando Francisco de Carvajal en una de sus jornadas de guerra, topó un fraile lego, y como entonces no los había legos en aquella mi tierra ni sé que ahora los haya, sospechando que era espía quiso ahorcarle, y por hacerlo con alguna más certificación, le convidó a comer; y para experimentar si era fraile o no, mandó que le diesen de beber en un vaso mayor que los ordinarios, para ver si lo tomaba con ambas manos o con una, y viéndole beber a dos manos, se certificó que era fraile y le dijo: «Beba, padre, beba; que la vida le da; beba, que la vida le da». Díjole esto porque si no bebiera así, se certificaba en su sospecha y lo ahorcaba luego ${ }^{37}$.

Su condición de cuentecillo tradicional indiano es puesta en evidencia por Gonzalo Correas, quien presenta esta versión:

Beba padre que la vida le da. Este es dicho de Garay, tirano en las Indias; fueron a tratar con él medios de paz dos religiosos, y él dudaba si eran fingidos, y para saberlo convidolos a comer, y púsoles delante sus porcelanas, pareciéndole que si las tomaban a dos manos como los religiosos en su convento, no eran fingidos, y al beber, viendo a un fraile que tomaba la taza con las dos manos, dijo: «Beba, padre, que la vida le da», y porque si eran fingidos, tenía intención de colgarlos, como él lo declaró después, y quedó por refrán ${ }^{38}$.

Ora el tirano Garay (en la versión de Correas), ora Carbajal (en la versión de Garcilaso), el protagonista del cuentecillo ha de ser, en cualquier otra versión que aparezca, un conquistador sanguinario y cruel. Para lo que atañe a la esencia del cuentecillo, los nombres de Garay o Carbajal eran accesorios. Lo que no se podía alterar mayormente eran el tiempo y lugar del hecho narrado: América durante el periodo de la conquista, es decir primera mitad del XVI, antes de la constitución del orden virreinal. Asimismo, no descartemos una reminiscencia de Lope de Aguirre, personaje que, bien visto, fue un auténtico «tirano en Indias», en aquel oscuro Garay que se mienta en el Vocabulario de refranes.

Acabo con un cuentecillo indiano escondido en una frase proverbial, que también nos permite observar vacilaciones de nombres en su transmisión. Es el caso de «El salto de Alvarado», frase que Correas menciona a propósito de una equi-

36. En torno a su figura cómica dentro de la tragedia que se configura en la Historia general del Perú, remito a Rodríguez Mansilla, 2007.

37. Garcilaso de la Vega, Historia general del Perú, libro V, cap. XLI, p. 396.

38. Correas, Vocabulario de refranes, p. 80. 
valente: «El salto de Hernandillo. Dícese de los grandes saltos; fue también en las Indias, como el de Alvarado» ${ }^{39}$. Se refiere a un célebre salto que se atribuye a Pedro de Alvarado escapando de México junto a Cortés. Lo narra Francisco López de Gómara en el capítulo CX de la Historia de la conquista de México: «Llegó [Alvarado] a la puente cabecera, y saltó de la otra parte sobre la lanza; de este salto quedaron los indios espantados y aun españoles, que era grandísimo y que otros no pudieron hacer, aunque lo probaron, y se ahogaron» ${ }^{40}$. Bernal Díaz del Castillo lo menciona, de paso, como un hecho apócrifo, porque no puede acreditarse por falta de testigos fidedignos que lo validen:

En la triste puente, que dijeron después que fue el salto de Alvarado, digo que en aquel tiempo ningún soldado se paraba a vello si saltaba poco o mucho, porque harto teníamos que salvar nuestras vidas, porque estábamos en gran peligro de muerte, según la multitud de mexicanos que sobre nosotros cargaban. Y todo lo que en aquel caso dice Gómara es burla [...] Y nunca oí decir deste salto de Alvarado hasta después de ganado México, que fue en unos nibelos [libelos] que puso un Gonzalo de Ocampo, que por ser algo feos aquí no declaro ${ }^{41}$.

Más allá de desmentir a Gómara, Bernal Díaz da por sentada la gran popularidad del «salto de Alvarado». Una popularidad que, no obstante, convivía con la de Hernandillo, al menos en la versión que recogió Correas. Se comprueba el fenómeno que se observó con «La prueba del fraile»: de Hernandillo a Alvarado había poca diferencia en términos de la anécdota, dejando de lado la veracidad de la atribución, tan insignificante para los fines del narrador oral como Carvajal o Garay. Lo esencial era que el salto había tenido lugar en las Indias en un contexto de aventura en el que esas hazañas, en principio increíbles, eran posibles.

Finalmente, la crítica de Bernal Díaz invita a reflexionar también sobre el surgimiento y la transmisión de muchas anécdotas de la conquista: la circulación de noticias, tanto con buena intención (propagar la fe) como con la mala (el libelo), es el punto de partida para generar cuentecillos que van acumulando variaciones. Al margen de nombres de personajes o detalles secundarios, el núcleo del cuentecillo se basa en lo admirable o curioso, rasgo esencial de la experiencia del Nuevo Mundo. Incluso cuando se trata de los cuentecillos que tienen evidente origen peninsular (como «el hombre que volaba» 0 «el brindis de los curacas»), estos se ven renovados al trasladarse a tierras americanas. Más interesante todavía se muestra la forma de caracterizar al personaje del soldado, el cual oscila entre dos polos: el del paradigmático Lancero, con remota identificación con Longinos y, bien visto, una versión positiva del fanfarrón de la literatura de la época; y el del cruel Carvajal. En el primer caso, la representación del soldado se alimenta de religiosidad y es un ejemplo más del providencialismo que justificaba la conquista en la mentalidad de la época.

39. Correas, Vocabulario de refranes, p. 82.

40. López de Gómara, Historia de la conquista de México, pp. 173-174

41. Díaz del Castillo, Historia verdadera, cap. CXXVIII, p. 482. A propósito de la anécdota de Alvarado, en nota complementaria (p. 1343) a su edición, Guillermo Serés evoca «el salto que dio el rey Richalte», del cuento III de El conde Lucanor, aunque lo encuentro algo remoto. 
En conclusión, un catálogo de cuentecillos indianos debería considerar: cuentecillos ambientados en Indias que tienen origen español, generalmente medieval («solo le falta la cola» o «el brindis de los curacas»); cuentecillos cuya americanidad se diluye, porque se vuelve secundaria («juega el sol antes que nazca»); cuentecillos indianos propiamente dichos, asociados con anécdotas de la conquista, generalmente con soldados como protagonistas, ora devotos o sanguinarios («el salmo de Lancero» y «la prueba del fraile»). Ciertamente, esta clasificación se basa, por motivos de espacio, en evidencia limitada, por lo que no la propongo como criterio discriminador en una recopilación, sino como una forma de ordenar los cuentecillos. Un mayor conocimiento de esta parcela de la cultura aurisecular en su intercambio con América contribuiría a campos tan diversos como la anotación filológica, la historia o los estudios interdisciplinarios dedicados a los siglos XVI y XVII.

\section{BiBLIOgRAFÍA}

Acosta, Josef de, Historia natural y moral de las Indias, ed. Fermín del Pino Díaz, Madrid, Consejo Superior de Investigaciones Científicas, 2008.

Bataillon, Marcel, Novedad y fecundidad del «Lazarillo de Tormes», Salamanca, Anaya, 1968.

Berceo, Gonzalo de, Milagros de Nuestra Señora, ed. Michael Gerli, Madrid, Cátedra, 1997.

Calderón de la Barca, Pedro, Entremeses, jácaras y mojigangas, ed. Evangelina Rodríguez Cuadros y Antonio Tordera, Madrid, Castalia, 1982.

Correas, Gonzalo, Vocabulario de refranes y frases proverbiales, Madrid, Real Academia Española, 1906.

Cov. = Covarrubias, Sebastián de, Tesoro de la lengua castellana o española, ed. Ignacio Arellano y Rafael Zafra, Madrid/Frankfurt Am Main, Iberoamericana/ Vervuert, 2006.

Chevalier, Maxime, Folklore y literatura. El cuento oral en el Siglo de Oro, Barcelona, Crítica, 1978.

Chevalier, Maxime, Cuentos folklóricos españoles del Siglo de Oro, Barcelona, Crítica, 1983.

Delicado, Francisco, La Lozana andaluza, ed. Bruno Damiani, Madrid, Castalia, 1990.

Díaz del Castillo, Bernal, Historia verdadera de la conquista de la Nueva España, ed. Guillermo Serés, Madrid, Real Academia Española, 2015.

Eliade, Mircea, The Myth of the Eternal Return or, Cosmos and History, Princeton, Princeton University Press, 1971.

Fradejas Lebrero, José, Más de mil y un cuentos del Siglo de Oro, Madrid/Frankfurt Am Main, Iberoamericana/Vervuert, 2008. 
Garcilaso de la Vega, Inca, Comentarios reales de los incas, I, ed. Ángel Rosenblat, Buenos Aires, Emecé, 1943.

Garcilaso de la Vega, Inca, Historia general del Perú, II, ed. Ángel Rosenblat, Buenos Aires, Emecé, 1944.

Garcilaso de la Vega, Inca, La Florida del Inca, ed. Emma Susana Speratti Piñero, México, Fondo de Cultura Económica, 1956.

Lida de Malkiel, María Rosa, «El fanfarrón en el teatro del Renacimiento», en Estudios de literatura española y comparada, Buenos Aires, Eudeba, 1966, pp. 173-202.

López de Gómara, Francisco, Historia de la conquista de México, ed. Jorge Gurria Lacroix, Caracas, Biblioteca Ayacucho, 1979.

López de Úbeda, Francisco, La pícara Justina, ed. Luc Torres, Madrid, Castalia, 2010.

Martínez, Miguel, Front Lines. Soldiers' Writing in the Early Modern Hispanic World, Philadelphia, University of Pennsylvania Press, 2016.

Murúa, fray Martín de, Los amores de Acoytapia y Chuquillanto y otras narraciones, ed. Ricardo Silva Santisteban, Lima, Editorial San Marcos, 2009.

Núñez Cabeza de Vaca, Álvar, Naufragios, ed. Juan Francisco Maura, Madrid, Cátedra, 1989.

Poema de mio Cid, ed. Colin Smith, Madrid, Cátedra, 1998.

Quevedo, Francisco de, Prosa festiva completa, ed. Celsa Carmen García Valdés, Madrid, Cátedra, 1993.

Rodríguez Mansilla, Fernando, «Francisco de Carvajal, vir facetus en el libro V de la Historia general del Perú», Boletín de la Academia Peruana de la Lengua, 44, 2007, pp. 61-76.

Rodríguez Mansilla, Fernando, «A vueltas con el brindis de los curacas: un cuentecillo tradicional en la literatura peruana», Boletín de literatura oral, 4, 2014, pp. 53-61.

Salas Barbadillo, Alonso Jerónimo de, El caballero puntual, ed. Enrique López Martínez, Madrid, Anejos de la Real Academia Española, 2016.

Salas Barbadillo, Alonso Jerónimo de, La peregrinación sabia y El sagaz Estacio, marido examinado, ed. Francisco A. Icaza, Madrid, Ediciones de La Lectura, 1924.

Sánchez Jiménez, Antonio, Leyenda Negra. La batalla sobre la imagen de España en tiempos de Lope de Vega, Madrid, Cátedra, 2016. 